$\begin{array}{lcl}\text { Opentham OPEN } & \text { Open Medicine Journal } \\ \text { CrossMark } & \text { Content list available at: www.benthamopen.com/MEDJ/ } \\ \text { DOI: } 10.2174 / 1874220301603010352 & \text { Open } \\ \text { ledicine } \\ \text { lournal }\end{array}$

REVIEW ARTICLE

\title{
Is There a Link Between Cholesterol Level and the Risk of Developing Depression?
}

\author{
Marlena Broncel* and Katarzyna Serejko-Banaś \\ Department of Internal Diseases and Clinical Pharmacology, Faculty of Military Medicine, Medical University of \\ Lodz, Poland
}

\begin{abstract}
Depressive disorders and hypercholesterolemia are serious and common global problems. Many researchers have attempted to demonstrate association between concentration of the lipid fractions, depression as well as the rate of suicide, but the results are inconclusive. To overcome this lack of knowledge, we have summarized the studies concerning this relationship and published in recent years. All of articles included were published in peer reviewed journals and were identified through systematic query of PubMed with follow-up manual searches.
\end{abstract}

Concentrations of total cholesterol - TC, cholesterol - LDL-C, cholesterol - HDL-C other triglycerides and others atherogenic index and comorbidity with depressive disorders have been considered. While both positive and negative association between lipid fractions and depression have been shown in many studies, some data revealed no relationships between the two factors. In addition, we have also summarized the usage of statins and the occurrence of depressive disorders, and the results remain inconclusive.

In conclusion, our review did not reveal a clear relationship between lipid fractions and depression. Additional studies are needed as increased incidence of comorbidity between mood disorders and lipid disorders have been observed.

Keywords: Depression, Depressive Disorders, Lipids, Statins, Suicide.

\section{INTRODUCTION}

Depressive disorders constitute one of main causes of disability and long-term inability to work. The disorders affect about 350 million people all around the world, i.e. $6 \%$ of the whole population [1]. It is believed that in 2030 depression will become the most common chronic disease observed in developed countries [2]. There are two diagnostic classification of depression: International Statistical Classification of Diseases and Related Health Problems (ICD-10) and Diagnostic and Statistical Manual of Mental Disorders (DSM V) (Table 1). Negative symptoms which should have lasted at least for two weeks include: mood depression, reduced psychomotor performance, loss of interests, lack of ability to feel pleasure, less energy. Some other symptoms include: difficulty in concentrating, loss of appetite, sleeping problems, low self-esteem. Besides, the DSM V classification lists criteria which exclude endogenous depression, e.g. somatic or organic factors affecting mood. There are terminological discrepancies: the ICD-10 classification gives the term "severe depressive disorder" and the DSM V classification - " major depressive disorder".

Causes of endogenous depression have not been clearly specified. There are many various neurobiological theories of depression:genetic vulnerability, altered HPA axis activit, dysfunctions of certain brain areas, neuronal atrophy and loss, changeable GABAergic and glutaminergic activity, neurochemical - shortage of biogenic amines (serotonin, norepinephrine, dopamine), disturbances in the circadian rhythm and biological clock with regards to serotonin excretion [3], inflammatory - increase in the level of IL-1 $\beta$, IL6, and TNF $\alpha$ [4].

\footnotetext{
* Address correspondence to this author at the Department of Internal Diseases and Clinical Pharmacology, Faculty of Military Medicine, Medical University of Lodz, Poland, WSS im. Bieganskiego, ul. Kniaziewicza 1/5 91-347 Łódź, Poland; Tel: +48 422516243 ; E-mail: marlena.broncel@umed.lodz.pl
} 
A few groups of drugs with various activity mechanisms can be applied in depression therapy. They include: tricyclic antidepressants (TCAs), selective serotonin reuptake inhibitors (SSRIs), serotonin-norepinephrine reuptake inhibitors (SNRIs), noradrenergic and specific serotonergic antidepressant (NaSSAs), tetracyclic antidepressants (TeCAs), monoamine oxidase inhibitors (MAOIs)

Table 1. Diagnosing depression according to the ICD-10 and DSM V.

\begin{tabular}{|c|c|}
\hline ICD-10 & DSM V \\
\hline $\begin{array}{l}\text { Two of three given symptoms observed } \\
\text { for a period of two weeks: } \\
\text { - mood depression } \\
\text { - loss of interests and anhedonia } \\
\text { - less energy or fatigue tolerance }\end{array}$ & $\begin{array}{l}\text { Minimum five of symptoms given below observed for a period of } 2 \text { weeks, on condition they are a } \\
\text { significant change in the patient's behaviour (one of indications is mood depression, loss of interests, } \\
\text { lack of ability to feel pleasure): } \\
\text { - difficulty concentrating } \\
\text { - low self-esteem } \\
\text { - feeling of guilt, feeling of worthlessness } \\
\text { - pessimistic vision of future } \\
\text { - suicidal thoughts or behaviour or autoaggressive behaviour } \\
\text { - sleeping difficulty } \\
\text { - loss of appetite. }\end{array}$ \\
\hline $\begin{array}{l}\text { Two or more than two symptoms } \\
\text { observed for a period of two weeks: } \\
\text { - difficulty concentrating } \\
\text { - low self-esteem } \\
\text { - feeling of guilt, feeling of worthlessness } \\
\text { - pessimistic vision of future } \\
\text { - suicidal thoughts or behaviour or } \\
\text { autoaggressive behaviour } \\
\text { - sleeping difficulty } \\
\text { - loss of appetite. }\end{array}$ & $\begin{array}{l}\text { Exclusion criteria: } \\
\text { - somatic or organic factors which might affect mood should be excluded } \\
\text { - reaction to death of a close person is not considered a disorder (however, if the feeling lasts longer and } \\
\text { the patient has suicidal thoughts, feels less and less worthy, demonstrates bradykinesia, we should } \\
\text { suspect endogenous depression) } \\
\text { - elusions are not observed before, during and after the period of disturbances for two weeks. }\end{array}$ \\
\hline
\end{tabular}

For many years the scientists have been arguing about the role of lipids, phospholipids in the function of the serotonergic system. In 1992 Engelberg [5] put forward a hypothesis on a relationship between low cholesterol levels and impaired function of the serotonergic system. In his opinion low cholesterol levels might contribute to disturbances in the liquidity of cell membranes and this, in turn, might affect functions of receptors, enzyme activity and transmembrane transport, including serotonin reuptake in brain cells. In the same year Lancet Journal published results of a study conducted by Severs [6]. In his article he refuted Engelberg's theory by claiming that regulatory mechanisms of cells are independent of cholesterol levels. Two years later Ringo et al. confirmed there is no significant relationship between cholesterol levels and levels of serotonin metabolites in the brain [7].

Over several decades there have been study findings concerning a relationship between the level of various lipid fractions (total cholesterol - TC, low-density lipoprotein- LDL-C, high-density lipoprotein - HDL-C) and depression risk, the recurrence of the disease recurrence, suicidal attempts. The results are quite divergent. Some of them indicate there is a significant correlation between low TC levels, the Castelli Index (TC/HDL-C) and an increased risk of depressive disorders. In other studies such observances were not made. More doubts appeared after introducing statins on the pharmaceutical market. Statins are strong low lowering cholesterol drugs. It was initially believed that intensive treatment might induce depression or exacerbate it, or increase the risk of suicidal attempts. Meta-analyses of extensive randomized studies on statins did not confirm those beliefs [8]. It is important because these drugs apart from being used in anti-atherosclerosis therapy are also applied in patients with depression which is a risk factor of cardiovascular diseases (CVD), including myocardial infarcts, cerebral strokes [1,9].

The authors of this article attempted to consolidate relevant studies conducted for the purpose of answering the question whether there is a correlation between serum cholesterol and the onset of depression. Recently published studies were taken from systematic and manual searches of the PubMed database. Of the 35 articles identified as relevant, 22 were published in high-impact journals. Only two of the articles reviewed were found in journals of an IF below 2.0; the remaining articles having been published in journals of an IF between $2.2-13.5$. Due to the published results having been derived from non-randomized trials, all of the studies analyzed are observational studies. The authors of this study did not take case reports into account. The study groups presented differed in sample size (30 to 29133) as well as in study duration (1 month to 8 years). A considerable diversity in the types and degree of severity of depression was presented. In the year preceding this article, a meta-analysis [10] was published concerning the correlation between the development of depression and only one cholesterol fraction - LDL. However, the results of this meta-analysis are unreliable, its statistical analysis is limited, and the remaining fractions of cholesterol were disregarded. 


\subsection{Total Cholesterol, LDL-Cholesterol and the Risk of Depression}

At the end of the 1980s and the beginning of the 1990s scientist conducted studies on a relationship between TC levels and the risk of depression. The first study on this issue was performed by Partonen et al. [11] on a large number of male patients, i.e. 29, 133, aged 50-69 years old. The researchers confirmed that patients with low TC levels were more often hospitalized due to major depressive disorders (MDD) and demonstrated mood disturbances [11]. However, it should be pointed out that mean values of TC were high both in the group of patients with depressive disorders (238.6 $\mathrm{mg} / \mathrm{dl})$ and in the control group $(241.7 \mathrm{mg} / \mathrm{dl})$ and the difference, despite a substantial statistical significance $(\mathrm{p}<0.001)$, was only $3.1 \mathrm{mg} / \mathrm{dl}$. The study had been conducted before statins were widely applied in therapies so this conclusion was drawn too soon.

In another study, conducted by Lindberg et al. [12], it was confirmed that patients with low TC and LDL-C values demonstrated mood depression. Of the total number of 644 male subject included in the study, 160 males often or very often reported mood depression within a period of one month since they the day of their inclusion in the study. The patients in this group demonstrated lower means of LDL-C and TC levels in comparison with the remaining 484 patients with no mood disturbances or with rare incidents of mood disturbances $(136.9 \mathrm{mg} / \mathrm{dl} v s 148.1 \mathrm{mg} / \mathrm{dl}, \mathrm{p}<0.001$ and $212.7 \mathrm{mg} / \mathrm{dl} v s 224.3 \mathrm{mg} / \mathrm{dl}, \mathrm{p}<0.002$ respectively) and the values were statistically significant. In females with mood depression who were included in a six-month observation the researchers also observed lower TC and LDL-C levels in comparison to healthy female subjects and the values were $210.8 \mathrm{mg} / \mathrm{dl}$ and $130.7 \mathrm{mg} / \mathrm{dl} \mathrm{respectively}$. The main limitation of the study was the fact that mood disturbances were diagnosed only on the base of the questionnaire and without clinical verification, according to DSM-V and ICD-10 recommendations. In a study conducted many years later by Tedders et al. [13] on 4,115 males and 4,275 females, aged $\geq 18$ years, U-shaped association was observed between the LDL-C and severe depression in men. Using the intermediate quartiles as the reference level, the ORs of severe depression for men with lower quartile and upper quartile LDL-C were 4.88 (1.80 - 13.29) and 2.43 (1.06 - 5.55) respectively. A significant reverse correlation between HDL-C and depressive mood were observed in women. The means of HDL-C were 59.25 (0.52), 57.00 (0.54), and $52.09(0.20) \mathrm{mg} / \mathrm{dl}$ respectively for women with no depression symptom, mild-moderate depression, and severe depression respectively ( $\mathrm{p}$-for trend test $<0.001$ ). The researchers confirmed no relationship between cholesterol levels and moderate depression either in females or in males.

In 102 patients ( 71 females, 31 males) with diagnosed MDD (on the base of the DSM-IV) above 20 scores on the Hamilton Depression Rating Scale) without concomitant diseases who were not administered low lowering cholesterol drugs, in the exacerbation period the authors observed significantly lower levels of TC and LDL-C ( $<<0.05)$ in comparison with lipid levels in the remission period [14]. Mean values of TC and LDL-C with current MDD in the group of patients without suicidal thoughts and tendencies were respectively $237 \mathrm{mg} / \mathrm{dl}(\mathrm{n}=33)$ and $137 \mathrm{mg} / \mathrm{dl}(\mathrm{n}=31) v \mathrm{~s}$ $272 \mathrm{mg} / \mathrm{dl}$ and $154 \mathrm{mg} / \mathrm{dl}$ in the asymptomatic period. In the group of patients with suicidal thoughts and tendencies were even lower, i.e. $170 \mathrm{mg} / \mathrm{dl}, 92.2 \mathrm{mg} / \mathrm{dl} v s 229 \mathrm{mg} / \mathrm{dl}$ and $126 \mathrm{mg} / \mathrm{dl}$. The lowest levels of TC and LDL-C were noted in patients after suicidal thoughts, i.e. $155 \mathrm{mg} / \mathrm{dl}, 92.8 \mathrm{mg} / \mathrm{dl} v s 229 \mathrm{mg} / \mathrm{dl}$ and $119 \mathrm{mg} / \mathrm{dl}$ in the remission period. The authors pointed out at significantly lower levels of TC and LDL in patients period ( $\mathrm{n}=30$ ), which were $229 \mathrm{mg} / \mathrm{dl}$ and $116 \mathrm{mg} / \mathrm{dl}$, and in patients without suicidal thoughts and tendencies in the remission period $(\mathrm{n}=31)$, which were 272 $\mathrm{mg} / \mathrm{dl}$ and $154 \mathrm{mg} / \mathrm{dl}$. The results were the grounds for drawing a conclusion that low levels of LDL-C $(\leq 160 \mathrm{mg} / \mathrm{dl})$ in patients with a MDD episode can be a risk factor of a suicidal attempt and in patients in the remission period they can be a prognosis factor for suicidal attempts during further recurrence of the disease.

Jow et al. [15] observed lowest mean TC levels $(166 \mathrm{mg} / \mathrm{dl})$ in patients with depression $(\mathrm{n}=69)$ (diagnosed on the base of the DSM-IV) in comparison with schizophrenia patients $(\mathrm{n}=78,199 \mathrm{mg} / \mathrm{dl}, \mathrm{p} \leq 0.001)$ and healthy subjects $(\mathrm{n}=51,185 \mathrm{mg} / \mathrm{dl}, \mathrm{p}<0.001)$. Ancelin et al. [16] observed that the relationship between certain cholesterol fractions and depression might depend on the sex of the patient. In males with depressive disorders $(\mathrm{n}=752)$, aged above 65 years, low LDL-C levels ([OR] 1.90; 95\%, [CI] = $1.25-2.89, \mathrm{p}=0.003)$ correlated with an increased risk of depression and in females with depressive disorders $(\mathrm{n}=1040)$ such a risk factor was low HDL-C level $([\mathrm{OR}] 1.42 ; 95 \%$, $[\mathrm{CI}]=1.04-1.94$, $\mathrm{p}=0.03$ ). The study conducted by Ancelin confirmed observations made by Engelberg [5], concerning a relationship between reduced LDL-C level in the plasma and decreased brain cell membrane cholesterol, which in consequence might lead to changes in density and functioning of serotoninergic transporters or receptors.

Fang et al., in a study conducted on 225 young females (the mean age was 27 years) in 2013 [17], confirmed a relationship between depression and low LDL-C levels.

Das et al. in their study conducted in 2010 [18] on a group of 30 patients with diagnosed depression (DSM-IV, 
above 7 scores on the Hamilton Depression Rating Scale) obtained higher values of TC levels (192.3 mg/dl) in patients with MDD in comparison with a group of healthy subjects $(163.3 \mathrm{mg} / \mathrm{dl}, \mathrm{p}<0.004)$. The mean age of the patients was 41 years; $60 \%$ of them were females and $60 \%$ of the females were of Indian origin. The authors confirmed a relationship between the degree of depression and the lipid level. In moderate depression $(n=17)$ the levels of particular lipid fractions, i.e. very low density lipoprotein (VLDL) and TC were $24.4 \mathrm{mg} / \mathrm{dl}, 176.88 \mathrm{mg} / \mathrm{dl}$ respectively. In severe depression $(\mathrm{n}=13)$ the values were significantly higher: $26.98 \mathrm{mg} / \mathrm{dl}(\mathrm{p}=0.03), 212.62 \mathrm{mg} / \mathrm{dl}(\mathrm{p}=0.03)$.

The studies discussed above demonstrate statistical significance in their results. Taking the absolute values of LDL and TC into account, the differences among these values are negligible. Given these minor variations, any conclusions drawn from their respective results are inconclusive.

A sound example of the degree of scientific accuracy in the above conclusions is the study undertaken by Partonen et al. [11]. Despite the fact that the subject group in this study was the most numerous of the ones discussed $(29,133)$, the difference in absolute values between the study group and control group for TC was $3,1 \mathrm{mg} / \mathrm{dl}$ at a statistical significance of $\mathrm{p}<0.001$. This study has been frequently cited for many years, however its conclusions are of little scientific value. A definitive answer to presence of a correlation between depression and lower values of TC or LDL is not demonstrated in the published data below, including for the many groups of subjects $[12,13,16]$ for which the absolute values between the study and control groups are greater and with substantial statistical significance. This is also evident in those studies in which groups smaller subject groups were tested $[14,15,17]$. The exception remains the study by Das et al. [18], in which higher values of TC were found in people suffering from depression versus a control group without depression. The small sample size as well as the statistical significance of $\mathrm{p}=0.03$ of this study garners special attention. It is also interesting to note the routine division of subjects into male and female subgroups in the aforementioned studies, in light of the fact that values of LDL and TC are independent of gender. From the point of view of the authors of this study, conclusions of higher scientific merit could potentially be reached had differentiating parameters been examined in the studies discussed, such as CVD in the medical and family history. An analysis of these parameters could allow for the influence of familial hypercholesterolemia to be compared separately with the respective control groups. It would also be relevant to narrow the age ranges into which the subjects were subdivided.

\subsection{Lack of Relationship Between Lipid Levels and Depression}

It is still controversial whether low cholesterol levels contribute to the occurrence of depression. Authors of studies conducted on small $(n=30-50)$ and big $(n=150-200)$ groups of patients did not confirm any significant relationship between the degree of depression and TC levels [19 - 23]. Maes et al. [20] divided patients with unipolar depression into three subgroups: with minor $(\mathrm{n}=16)$, simple major $(\mathrm{n}=14)$ and melancholic depressive disorders $(\mathrm{n}=17)$. The control group consisted of 26 healthy subjects. The authors did not note any significant relationship between selected lipid parameters and types of depressive disorders. It is worth mentioning that in 12 relatives of the patients with melancholic depressive disorders from subgroup 3 the authors observed lower estrified cholesterol ratio than in healthy subjects.

In 152 young patients (aged $12-21$ years old) there was no significant relationship between the degree of depression diagnosed with the application of the Beck Depression Inventory and TC levels [21]. Huang et al. [22] drew similar conclusions after conducting a study on 213 Taiwanese patients, including 61 with affective disorders. They did not observe any correlation with TC levels and the occurrence of mania or MDD, suicidal attempts, aggression symptoms. A few years later the same researchers analyzed lipid levels depending on the type of depression in 142 patients [23]. The levels of TC, LDL-C and atherogenicity ratios did not differ in patients with melancholic depression, atypical depression and dysthymia. The authors, however, observed significantly higher concentrations of triglycerides TG $(164.1 \mathrm{mg} / \mathrm{dl})$ and VLDL $(52.4 \mathrm{mg} / \mathrm{dl})$ in males with melancholic features of MDD in comparison with atypical depression $(124.8 \mathrm{mg} / \mathrm{dl}$ and $25.0 \mathrm{mg} / \mathrm{dl})$. In females with atypical depression the level of HDL-C (48.4 mg/dl) was significantly lower in comparison with melancholic depression $(51.4 \mathrm{mg} / \mathrm{dl})$.

In 2006 Chen et al. [24] published findings of a two-year study conducted on a group of 69 menopausal females with diagnosed depression (DSM-IV). He did not note any relationship between TG, TC, HDL-C, VLDL, LDL-C levels, TC/HDL and LDL/HDL ratios and the occurrence of depressive disorders.

In the current literature, there are fewer studies indicating the lack of any correlation between lipid concentration and depression than those that indicate the presence of such a correlation [19 - 23]. The studies discussed in this investigation affect much smaller subject groups (up to $n=200$ ) than the studies illustrating the correlation between lipid concentration and depression. Further subdivision of subjects based on different types of depression narrows the 
number of subjects into even smaller groups (no more than $n=20$ ) [20]. The identification of depressive disorders had only been identified from the age of 12 is an unreliable criterion upon which to examine any correlation with lipid concentration, similarly as it would be to examine such a correlation based on subjects' nationality [22]. From the point of view of the authors of this study, the correlation between the onset of depression and lipid concentration in women and/or men should be determined first; only afterward should the correlations with different types of depression be differentiated. It must be noted that most of these studies were published in journals lacking an IF. As in the above summary, there is emphasis on statistical significance as well as on minor differences in the absolute values. Studies indicating a lack of any correlation between lipid concentration and depression seem to have been undertaken with less diligence and are therefore of lesser scientific value.

\subsection{HDL-C and Risk of Depression}

One of the most extensive studies was the one carried out by van Reedt Dortland-n=2981 [29]. Its author observed lower HDL-C levels in patients with melancholic depression and higher TC and LDL-C levels in patients with atypical depression. Moreover, he noted lower HDL-C level and higher TG level in patients with current depression in comparison with remitted depression (respectively HDL-C: $59.2 \mathrm{mg} / \mathrm{dl} v s \quad 61.4 \mathrm{mg} / \mathrm{dl} \mathrm{p}=0.007 ; \mathrm{TG}: 104.8 \mathrm{mg} / \mathrm{dl} v s$ $97.1 \mathrm{mg} / \mathrm{dl}, \mathrm{p}=0.001$ ) and the control group (HDL-C $61.4 \mathrm{mg} / \mathrm{dl} \mathrm{p}=0.007$, TG 95.7mg/dl p=0.001).

Maes et al. [25] observed lower HDL-C levels in patients with MDD $(n=36)$ in comparison with 28 subjects from the control group. Among the patients with diagnosed MDD 14 suffered from melancholic depression. An analysis confirmed lower concentrations of $\mathrm{TC}=201 \mathrm{mg} / \mathrm{dl}(\mathrm{p}<0.05)$, HDL-C $=41 \mathrm{mg} / \mathrm{dl}(\mathrm{p}<0.001)$ and the ratio HDL/TC $\times 100=$ $25.6(p<0.05)$ in patients with depression in comparison with the control group, irrespective of sex. The authors did not confirm a relationship between the lipid level and melancholic depression, refractoriness to treatment, duration of the episode and the number of past episodes.

Sagud et al. [26] conducted a study on females (the mean age was 50.1 years) out of whom 41 were diagnosed with bipolar affective disease ( $\mathrm{n}=22$ in mania, $\mathrm{n}=19$ in depression) and 34 - with MDD. The last group, i.e. the control one, included 50 subjects. The authors noted statistically significant lower levels of HDL-C in patients with depression than in the control group $(48.3 \mathrm{mg} / \mathrm{dl} v s 67.7 \mathrm{mg} / \mathrm{dl}, \mathrm{p}<0.001)$ and did not note a correlation between levels of TC and LDL$\mathrm{C}, \mathrm{TC} / \mathrm{HDL}-\mathrm{C}$ and LDL- C/HDL-C ratios and depressive disorders.

Lehto et al. 2008 [27] conducted a study on 63 patients (the mean age was 54.68) with chronic depression (lasting up to 7 years) and compared them to 61 subjects from the control group (the mean age was 55.59). An analysis confirmed that patients with MDD demonstrated lower levels of HDL-C than healthy subjects $(54.1 \mathrm{mg} / \mathrm{dl} v s 61.5 \mathrm{mg} / \mathrm{dl}$, $\mathrm{p}<0.01)$. LDL-C/HDL-C and TC/HDL-C ratios in patients with depression were higher than in subjects from the control group (respectively: 2.41 vs $2.12 \mathrm{p}<0.044 ; 3.91$ vs $3.49 \mathrm{p}<0.026$ ). Another study conducted by Lehto et al. in 2010 [28] confirmed that the level of HDL-C in patients with chronic ( $\geq 3$ years) depression is lower than in patients who have been affected by depression for a shorter period of time $(48.7 \mathrm{mg} / \mathrm{dl} v s 58 \mathrm{mg} / \mathrm{dl}, \mathrm{p}=0.004)$.

To sum it section, in the studies discussed above points out small sample sizes and short time of observation. Some authors emphasize in their works that there is a relationship between low levels of HDL-C and a high risk of depression [25 - 29]. Most of these studies were conducted on a small group of patients, on average $n=50$ [25 - 28]; the duration of the diseases was different, up to $7-8$ years [27]. The mean age of the patients included in the study was 54 years and they had various types of depression, mainly atypical or melancholic [25, 29]. Healthy volunteers constituted the control group. The absence of more numerous subject groups comparing women and men serves to create a significant gap in the examination of this cholesterol fraction. It is an accepted fact in the scientific community that normal HDL values are different for each gender. The authors of the studies cited below had not taken these differences into account in their observations. Only Sagud [26] divided the subject groups by gender, however the small number of groups in that study casts doubt on the conclusions drawn.

\subsection{Atherogenicity Ratios and Depression}

Many researchers believe that atherogenicity ratios such as: TC/HDL-C, LDL-C/HDL-C, API (Atherogenic Index of Plasma) and $\mathrm{AC}$ (Atherogenic Coefficient) play an important role in the evaluation of the depression risk. In conducted studies they did not observe any changes in lipid levels but they noted that values of the ratios significantly correlated with an increased risk of depressive disorders [30 - 32]. However, there are striking differences with regards to types of these differences. 
Huang et al. [30] classified 162 studied patients into 3 groups according to symptoms they reported. The division was the following: patients with depressive disorders $(n=103)$, patients with anxiety disorders $(n=20)$, the control group - healthy subjects $(n=39)$. In one-year observation period he noted significantly lower values of TC/HDL-C and LDL$\mathrm{C} / \mathrm{HDL}-\mathrm{C}$ in depressive disorder patients than in subjects from the control group (respectively $3.8 v s 4.3 \mathrm{p}=0.013 ; 2.3 v s$ $2.6 \mathrm{p}=0.015)$. Besides, the authors also analyzed how male and female depression patients are affected by lipid disorders. In males the authors observed significantly higher HDL-C levels than in the control group (49.0mg/dl vs $47.3 \mathrm{mg} / \mathrm{dl}, \mathrm{p}<0.028)$ and lower values of the TC/HDL-C ratio (4.0 vs 4.2, $\mathrm{p}<0.01)$. In females with diagnosed MDD $\mathrm{TC} / \mathrm{HDL}-\mathrm{C}$ and LDL-C/HDL-C ratios were significantly lower in comparison to the control group (respectively $3.6 \mathrm{vs}$ 4.4 and 2.1 vs $2.6, \mathrm{p}<0.031)$.

Vargas et al. conducted a study on 92 patients with MDD, 49 patients with bipolar affective disorder and 201 subjects from a control group. They confirmed that Castelli risk ratio 1 and 2 are increased in the groups of patients with MDD and bipolar affective disorder and their values are 4.7, 3.0 and 4.8, 3.0 respectively and in the control group they were 4.2 and $2.6(\mathrm{p}<0.05)$. HDL-C levels were significantly lower in patients with bipolar affective disorder in comparison with the control group $(43.9 \mathrm{mg} / \mathrm{dl}$ vs. $49.2 \mathrm{mg} / \mathrm{dl}, \mathrm{p}<0.05)$. The same study did not confirm any significant correlations between patients with bipolar affective disorder, unipolar affective disorder and healthy subjects with regards to HDL-C levels [31]. Values of API and AC in patients with unipolar affective disorder were higher in comparison to values obtained in healthy subjects (API 0.138, AC 4.040 vs API 0.033, AC3.401; $\mathrm{p}=0.003$ and $\mathrm{p}=0.044$ respectively) and in patients with bipolar affective disorder, affected by depressed phases (API 0.130, AC 3.841; $\mathrm{p}=0.044, \mathrm{p}=0.074$ respectively) [32].

The above studies are of low scientific quality and poor statistical significance [30 - 32]. Atherogenic indicators play a minor role in current clinical practice, which may be the reason for the decreasing interest in research in this area.

\subsection{Statins and the Risk of Depression and Suicide}

Attempts to reduce the cholesterol level in healthy people, and such were made in the 1980s, demonstrated that such methods might lead to aggressive behaviour and suicide. Results of a multicentre, randomized double blind trial, conducted on almost 8000, males within primary prevention of ischaemic heart disease (The Lipid Research Clinics Coronary Primary Prevention Trial Results) indicated that a considerable reduction of cholesterol level, caused by the application of a low-fat diet as well as the administration of cholestyramine and gemfibrozil, did not significantly reduce mortality but contributed to a three-fold increase in the number of suicidal attempts and incidents of aggressive behaviours in the group of treated patients in comparison with the control group [33]. Muldoon et al. 1990 [34] made an analysis which included 6 randomized studies on primary prevention of ischaemic heart disease. In each of the studies the patients were administered a diet or low lowering cholesterol drugs or a diet and drugs. Obtained results were compared with the ones received in the control group. The analysis included almost 25,000 middle-aged males. The authors observed that the reduced level of cholesterol, induced by the administration of the diet or drugs, did not lead to a significant decrease in mortality caused by CVD in comparison with the control group ( $\mathrm{p}<0.06)$. Lower cholesterol levels correlated with an increased mortality risk due to other diseases in comparison with the control group ( $\mathrm{p}<0.004)$. Simultaneously, a $10 \%$ decrease in the level of cholesterol resulted in a decrease in the number of deaths due to CVD by $28 / 100,000$ but also in an increase in the number of deaths due to accidents, acts of violence or suicidal attempts by 29/100,000 (almost two-fold increase) in comparison with the control group.

An introduction of statins on the pharmaceutical market in the 1990s aroused a lot of anxiety among psychiatrists. In 2007 LaRosa et al. performed a study on a numerous group of patients. The authors selected patients with cardiovascular diseases and LDL $<130 \mathrm{mg} / \mathrm{dl}$. The group was randomized to atorvastatin therapy $10 \mathrm{mg}(\mathrm{n}=5006)$ and 80 $\mathrm{mg} /$ day $(\mathrm{n}=4995)$. The number of deaths due to cardiovascular problems and other diseases, including suicide, was smaller in patients with lower LDL levels [35].

Due to many extensive clinical studies it was proved that statins reduce the risk of cardiovascular episodes in primary and secondary prevention as well as decrease general mortality. The drugs are administered in patients after cardiovascular episodes, patients with diabetes, familial hypercholesterolemia, chronic renal failure. Apart from their hypolipidemic properties statins are characterized with other precious properties; they are anti-inflammatory, antioxidative, immunomodulating drugs which stabilize atherosclerotic plaque.

In 2012 O'Neil et al. [36] analyzed 7 randomized trials, i.e. 2,105 patients (1133 were administered statin and 972 placebo). The authors analyzed results of studies published in $1994-2006$. The studies included patients with 
hypercholesterolemia who have been treated with statin for at least two weeks. Mood disorders were monitored with the application of the Profile of Mood States (POMS). Neither the period of hypolipidemic treatment (4 weeks, $3-6$ months, $3-4$ years) nor the type of the administered statin contributed to a significant difference in POMS results. Beneficial anti-inflammatory and anti-oxidative properties of statins probably contributed to the lack of a relationship between the application of these drugs and mood disorders [4].

Table 2. Summary.

\begin{tabular}{|c|c|c|c|}
\hline Authors & Subject & Lipids in depression & \\
\hline [11] Partonen T, et al. & 29133 males & $\mathrm{TC}$ & $\downarrow$ \\
\hline \multirow{2}{*}{ [12] Lindberg G, et al. } & \multirow{2}{*}{644 males } & $\begin{array}{c}\mathrm{TC}, \mathrm{LDL} \delta \\
1 \text { month observation }\end{array}$ & $\downarrow$ \\
\hline & & $\begin{array}{c}\mathrm{TC}, \mathrm{LDL}+ \\
6 \text { months observation }\end{array}$ & $\downarrow$ \\
\hline \multirow[t]{2}{*}{ [13] Tedders ST, et al. } & \multirow[t]{2}{*}{4115 males and 4275 females } & $\begin{array}{l}\text { U-shaped association was observed between the LDL-C and severe } \\
\text { depression in men }\end{array}$ & \\
\hline & & HDL with severe depression $q$ & $\downarrow$ \\
\hline [14] Rabe-Jablonska J, et al. & 71 females and 31 males & $\begin{array}{c}\mathrm{TC}, \mathrm{LDL} \text {, the lowest in patients after suicidal thoughts and with } \\
\text { suicidal attempts in the remission }\end{array}$ & $\downarrow$ \\
\hline [15] Jow GM, et al. & 69 males and females & $\mathrm{TC}$ & $\downarrow$ \\
\hline \multirow{2}{*}{ [16] Ancelin ML, et al. } & \multirow{2}{*}{752 males and 1040 females } & LDL $\widehat{\sigma}$ & $\downarrow$ \\
\hline & & HDL $q$ & $\uparrow$ \\
\hline [17] Fang CY, et al. & 225 females & LDL +9 & $\downarrow$ \\
\hline [18] Das, et al. & 30 males and females & $\mathrm{TC}$ & $\uparrow$ \\
\hline [19] Bajwa WK, et al. & 60 males and females & No correlation with TC & \\
\hline [20] Maes M, et al. & 47 males and females & No correlation with estrified cholesterol and TC/HDL & \\
\hline [21] Apter A, et al. & 152 males and females & No correlation with TC & \\
\hline [22] Huang TL & 213 males and females & No correlation with TC & \\
\hline \multirow{2}{*}{ [23] Huang TL, et al. } & \multirow{2}{*}{142 males and females } & TG, VLDL $\delta$ with melancholic subtype depression & $\uparrow$ \\
\hline & & HDL $q$ with atypical subtype depression & $\downarrow$ \\
\hline [24] Maes M,et al.. & 36 males and females & HDL, TC, HDL/TC x 100 & $\downarrow$ \\
\hline [25] Chen CC, et al. & 69 females & No correlation & \\
\hline [26] Sagud M, et al. & 75 males and females & HDL & $\downarrow$ \\
\hline [26] Lehto SM, et al. & 63 males and females & $\begin{array}{c}\text { HDL } \\
\text { LDL/HDL i TC/HDL }\end{array}$ & $\begin{array}{ll}\downarrow \\
\uparrow \\
\end{array}$ \\
\hline [28] Lehto SM, et al. & 88 males and females & HDL & $\downarrow$ \\
\hline \multirow{2}{*}{ [29] van Reedt Dortland AK, et al. } & \multirow{2}{*}{2981 males and females } & HDL with melancholic subtype depression & $\downarrow$ \\
\hline & & TC, LDL with atypical subtype depression & $\uparrow$ \\
\hline \multirow{3}{*}{ [30] TL Huang, et al. } & \multirow{3}{*}{162 males and females } & HDL & $\uparrow$ \\
\hline & & TG with current depression & $\uparrow$ \\
\hline & & Castelli risk index 1 and 2 & $\downarrow$ \\
\hline [31] Heber Odebrecht Vargas, et al. & 141 males and females & Castelli risk index 1 and 2 & $\uparrow$ \\
\hline [32] Sandra Odebrecht Vargas Nunes, et al. & 134 males and females & API, AC & $\uparrow$ \\
\hline
\end{tabular}

Authors of a meta-analysis, carried out in 2014 on the same issue, made similar observations [37]. It included 7 observational studies ( 4 cohort, 2 nested case-control, and 1 cross-sectional) conducted in 5 different countries (9,187 studied subjects). The authors compared the studies and classified them in subgroups (longitudinal analysis vs. crosssectional studies, cohort vs. other studies, patients with cardiovascular diseases vs. healthy subjects). They did not observe any significant differences with regards to the occurrence of depression (respectively $p=0.7 ; 0.21 ; 0.41$ ). The authors implied in their conclusion that patients treated with statins might be less prone to develop depression in comparison with patients who have not been administered a statin therapy and this fact might result from antiinflammatory properties of these drugs.

Until the end of the $20^{\text {th }}$ century cholesterol was considered the only cause of atherosclerosis and coronary disease. For about 15 years researchers have been implying more and more frequently that atherosclerosis is an inflammatory disease [38, 39]. 
Similarly, the theory on inflammatory nature of depression is gaining more and more advocates and is vividly discussed in professional literature. Considering all the above, anti-inflammatory and anti-oxidative properties of statins seem to have a great potential not only in cardiology and neurology but also in psychiatry.

\section{LIMITATIONS}

A lack of randomized studies, high levels of cholesterol upon discharge (presently, values below $115 \mathrm{mg} / \mathrm{dl}$ are considered as low; $<25 \mathrm{mg} / \mathrm{dl}$ as very low), broad heterogeneity of study groups in the current literature, small sample sizes, inconsistent criteria for the diagnosis of depression, wide variation in the types and degrees of severity of depression.

\section{CONCLUSION}

It is impossible to draw a definitive conclusion on the basis of the aforementioned studies (Table 2). Conclusions based on all studies taken into account by the authors of this study are based on their statistical relevance. When absolute parameters were taken into account, very minor differences in absolute parameters were discernible among them. Furthermore, cholesterol values considered as low were interpreted as definitively high, or in the case of HDL, normal, in light of current knowledge (including the EAS 2016 guidelines). From the point of view of cardiovascular risk, the values cited should be reduced (pharmacologically or otherwise), with high-risk patients requiring pharmacological treatment only. An HDL value of $50 \mathrm{mg} / \mathrm{dl}$ is the goal of all forms of treatment. The above summary of current literature does not adequately address the possible consequences of low and very low values of LDL, TC (according to current standards) in the development of depression. Knowledge of the possible consequences is essential due to the fact that the number of patients who require pharmacological reduction of cholesterol is very large. Statins, the most popular hipolipidemic drugs, are only able to reduce cholesterol by up to $50 \%$. Current treatment includes inhibitors of PCSK9, during the course of which LDL is observed to fall below $25 \mathrm{mg} / \mathrm{dl}$. Based on this information, it is essential to determine the cut-off point below the risk of symptoms of depression developing becomes relevant. Therefore, further studies involving patients with lower cholesterol values must be conducted.

\section{CONFLICT OF INTEREST}

The authors confirm that this article content has no conflict of interest.

\section{ACKNOWLEDGEMENTS}

Declared none.

\section{REFERENCES}

[1] Maes M, Ruckoanich P, Chang YS, Mahanonda N, Berk M. Multiple aberrations in shared inflammatory and oxidative and nitrosative stress (IO and NS) pathways explain the co association of depression and cardiovascular disorder (CVD), and the increased risk for CVD and due mortality in depressed patients. Prog Neuro-Psychopharmacol Biol Psychiatry 2011; 35(3): 769-83.

[2] Mathers CD, Loncar D. Projections of global mortality and burden of disease from 2002 to 2030. PLoS Med 2006; 3(11): e442. [http://dx.doi.org/10.1371/journal.pmed.0030442] [PMID: 17132052]

[3] Hasler G. Pathophysiology of depression: do we have any solid evidence of interest to clinicians? World Psychiatry 2010; 9(3): 155-61. [http://dx.doi.org/10.1002/j.2051-5545.2010.tb00298.x] [PMID: 20975857]

[4] Duman RS. Pathophysiology of depression and innovative treatments: remodeling glutamatergic synaptic connections. Dialogues Clin Neurosci 2014; 16(1): 11-27. [PMID: 24733968]

[5] Engelberg H. Low serum cholesterol and suicide. Lancet 1992; 339(8795): 727-9. [http://dx.doi.org/10.1016/0140-6736(92)90609-7] [PMID: 1347593]

[6] Severs NJ. Low serum cholesterol and suicide Lancet. 1992; 339: p. (8799)1001. [http://dx.doi.org/10.1016/0140-6736(92)91589-Z]

[7] Ringo DL, Lindley SE, Faull KF, Faustman WO. Cholesterol and serotonin seeking a possible link between blood cholesterol and CSF 5HIAA Biol Psychiatry 1994; 35(12): 957-9.

[8] Muldoon MF, Manuck SB, Mendelsohn AB, Kaplan JR, Belle SH. Cholesterol reduction and non-illness mortality: meta-analysis of randomised clinical trials 2001; 35(12): 957-9. [http://dx.doi.org/10.1136/bmj.322.7277.11]

[9] Van der Kooy K, van Hout H, Marwijk H, Marten H, Stehouwer C, Beekman A. Depression and the risk for cardiovascular diseases: systematic review and meta analysis. Int J Geriatr Psychiatry 2007; 22(7): 613-26. 
[http://dx.doi.org/10.1002/gps.1723] [PMID: 17236251]

[10] Persons JE, Fiedorowicz JG. Depression and serum low-density lipoprotein: A systematic review and meta-analysis. J Affect Disord 2016; 206: 55-67.

[http://dx.doi.org/10.1016/j.jad.2016.07.033] [PMID: 27466743]

[11] Partonen T, Haukka J, Virtamo J, Taylor PR, Lönnqvist J. Association of low serum total cholesterol with major depression and suicide. Br J Psychiatry 1999; 175: 259-62. [http://dx.doi.org/10.1192/bjp.175.3.259] [PMID: 10645328]

[12] Lindberg G, Larsson G, Setterlind S, Råstam L. Serum lipids and mood in working men and women in Sweden. J Epidemiol Community Health 1994; 48(4): 360-3. [http://dx.doi.org/10.1136/jech.48.4.360] [PMID: 7964334]

[13] Tedders SH, Fokong KD, McKenzie LE, Wesley C, Yu L, Zhang J. Low cholesterol is associated with depression among US household population. J Affect Disord 2011; 135(1-3): 115-21.

[http://dx.doi.org/10.1016/j.jad.2011.06.045] [PMID: 21802743]

[14] Rabe-Jabłońska J, Poprawska I. Levels of serum total cholesterol and LDL-cholesterol in patients with major depression in acute period and remission. Med Sci Monit 2000; 6(3): 539-47. [PMID: 11208367]

[15] Jow GM, Yang TT, Chen CL. Leptin and cholesterol levels are low in major depressive disorder, but high in schizophrenia. J Affect Disord 2006; 90(1): 21-7. [http://dx.doi.org/10.1016/j.jad.2005.09.015] [PMID: 16324751]

[16] Ancelin ML, Carrière I, Boulenger JP, et al. Gender and genotype modulation of the association between lipid levels and depressive symptomatology in community-dwelling elderly (the ESPRIT study). Biol Psychiatry 2010; 68(2): 125-32. [http://dx.doi.org/10.1016/j.biopsych.2010.04.011] [PMID: 20537614]

[17] Fang CY, Egleston BL, Gabriel KP, et al. Depressive symptoms and serum lipid levels in young adult women. J Behav Med 2013; 36(2): $143-52$ [http://dx.doi.org/10.1007/s10865-012-9409-1] [PMID: 22382824]

[18] Das PP, Malhotra S, Chakrabarti S, Sharma S. Elevated total cholesterol in severely depressed patients: role in cardiovascular risk? World J Biol Psychiatry 2010; 11(2 Pt 2): 321-8. [http://dx.doi.org/10.3109/15622970902960889] [PMID: 19462342]

[19] Bajwa WK, Asnis GM, Sanderson WC, Irfan A, van Praag HM. High cholesterol levels in patients with panic disorder. Am J Psychiatry 1992; 149(3): 376-8

[http://dx.doi.org/10.1176/ajp.149.3.376] [PMID: 1536278]

[20] Maes M, Delanghe J, Meltzer HY, Scharpé S, DHondt P, Cosyns P. Lower degree of esterification of serum cholesterol in depression: relevance for depression and suicide research. Acta Psychiatr Scand 1994; 90(4): 252-8. [http://dx.doi.org/10.1111/j.1600-0447.1994.tb01589.x] [PMID: 7831994]

[21] Apter A, Laufer N, Bar-Sever M, Har-Even D, Ofek H, Weizman A. Serum cholesterol, suicidal tendencies, impulsivity, aggression, and depression in adolescent psychiatric inpatients. Biol Psychiatry 1999; 46(4): 532-41. [http://dx.doi.org/10.1016/S0006-3223(98)00345-X] [PMID: 10459404]

[22] Huang TL. Serum cholesterol levels in mood disorders associated with physical violence or suicide attempts in Taiwanese. Chang Gung Med J 2001; 24(9): 563-8. [PMID: 11725626]

[23] Huang TL, Chen JF. Lipid and lipoprotein levels in depressive disorders with melancholic feature or atypical feature and dysthymia. Psychiatry Clin Neurosci 2004; 58(3): 295-9. [http://dx.doi.org/10.1111/j.1440-1819.2004.01235.x] [PMID: 15149297]

[24] Chen CC, Huang TL. Association of serum lipid profiles with depressive and anxiety disorders in menopausal women. Chang Gung Med J 2006; 29(3): 325-30. [PMID: 16924895]

[25] Maes M, Smith R, Christophe A, et al. Lower serum high-density lipoprotein cholesterol (HDL-C) in major depression and in depressed men with serious suicidal attempts: relationship with immune-inflammatory markers. Acta Psychiatr Scand 1997; 95(3): $212-21$. [http://dx.doi.org/10.1111/j.1600-0447.1997.tb09622.x] [PMID: 9111854]

[26] Sagud M, Mihaljevic-Peles A, Pivac N, Jakovljevic M, Muck-Seler D. Lipid levels in female patients with affective disorders. Psychiatry Res 2009; 168(3): 218-21. [http://dx.doi.org/10.1016/j.psychres.2008.06.048] [PMID: 19560828]

[27] Lehto SM, Hintikka J, Niskanen L, et al. Low HDL cholesterol associates with major depression in a sample with a 7-year history of depressive symptoms. Prog Neuropsychopharmacol Biol Psychiatry 2008; 32(6): 1557-61. [http://dx.doi.org/10.1016/j.pnpbp.2008.05.021] [PMID: 18583011]

[28] Lehto SM, Niskanen L, Tolmunen T, et al. Low serum HDL-cholesterol levels are associated with long symptom duration in patients with major depressive disorder. Psychiatry Clin Neurosci 2010; 64(3): 279-83. [http://dx.doi.org/10.1111/j.1440-1819.2010.02079.x] [PMID: 20374538] 
[29] van Reedt Dortland AK, Giltay EJ, van Veen T, van Pelt J, Zitman FG, Penninx BW. Associations between serum lipids and major depressive disorder: results from the Netherlands Study of Depression and Anxiety (NESDA). J Clin Psychiatry 2010; 71(6): 729-36. [http://dx.doi.org/10.4088/JCP.08m04865blu] [PMID: 20021996]

[30] Huang TL, Wu SC, Chiang YS, Chen JF. Correlation between serum lipid, lipoprotein concentrations and anxious state, depressive state or major depressive disorder. Psychiatry Res 2003; 118(2): 147-53. [http://dx.doi.org/10.1016/S0165-1781(03)00071-4] [PMID: 12798979]

[31] Vargas HO, Nunes SO, Barbosa DS, et al. Castelli risk indexes 1 and 2 are higher in major depression but other characteristics of the metabolic syndrome are not specific to mood disorders. Life Sci 2014; 102(1): 65-71. [http://dx.doi.org/10.1016/j.lfs.2014.02.033] [PMID: 24607777]

[32] Nunes SO, Piccoli de Melo LG, Pizzo de Castro MR, et al. Atherogenic index of plasma and atherogenic coefficient are increased in major depression and bipolar disorder, especially when comorbid with tobacco use disorder. J Affect Disord 2015; 172: 55-62. [http://dx.doi.org/10.1016/j.jad.2014.09.038] [PMID: 25451396]

[33] Frick MH, Elo O, Haapa K, et al. Helsinki Heart Study: primary-prevention trial with gemfibrozil in middle-aged men with dyslipidemia. Safety of treatment, changes in risk factors, and incidence of coronary heart disease. N Engl J Med 1987; 317(20): 1237-45. [http://dx.doi.org/10.1056/NEJM198711123172001] [PMID: 3313041]

[34] Muldoon MF, Manuck SB, Matthews KA. Lowering cholesterol concentrations and mortality: a quantitative review of primary prevention trials. BMJ 1990; 301(6747): 309-14.

[http://dx.doi.org/10.1136/bmj.301.6747.309] [PMID: 2144195]

[35] LaRosa JC, Grundy SM, Kastelein JJ, Kostis JB, Greten H. Safety and efficacy of Atorvastatin-induced very low-density lipoprotein cholesterol levels in Patients with coronary heart disease (a post hoc analysis of the treating to new targets [TNT] study). Am J Cardiol 2007; 100(5): 747-52.

[http://dx.doi.org/10.1016/j.amjcard.2007.03.102] [PMID: 17719314]

[36] ONeil A, Sanna L, Redlich C, et al. The impact of statins on psychological wellbeing: a systematic review and meta-analysis. BMC Med 2012; 10: 154. [http://dx.doi.org/10.1186/1741-7015-10-154] [PMID: 23206308]

[37] Parsaik AK, Singh B, Murad MH, et al. Statins use and risk of depression: a systematic review and meta-analysis. J Affect Disord 2014; 160: $62-7$. [http://dx.doi.org/10.1016/j.jad.2013.11.026] [PMID: 24370264]

[38] Ridker PM. Testing the inflammatory hypothesis of atherothrombosis: scientific rationale for the cardiovascular inflammation reduction trial (CIRT). J Thromb Haemost 2009; 7(Suppl. 1): 332-9. [http://dx.doi.org/10.1111/j.1538-7836.2009.03404.x] [PMID: 19630828]

[39] Ross R. Atherosclerosis is an inflammatory disease. Am Heart J 1999; 138(5 Pt 2): S419-20. [http://dx.doi.org/10.1016/S0002-8703(99)70266-8] [PMID: 10539839]

(c) Broncel and Serejko; Licensee Bentham Open

This is an open access article licensed under the terms of the Creative Commons Attribution-Non-Commercial 4.0 International Public License (CC BY-NC 4.0) (https://creativecommons.org/licenses/by-nc/4.0/legalcode), which permits unrestricted, non-commercial use, distribution and reproduction in any medium, provided the work is properly cited. 